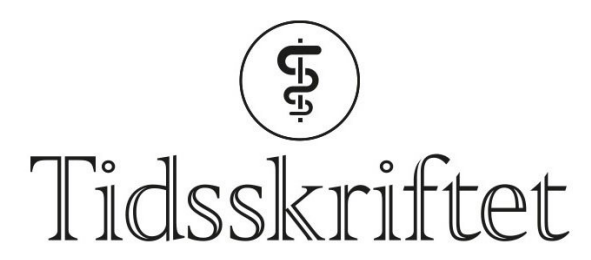

DEN NORSKE LEGEFORENING

\title{
Tordenskiolds obduksjonsrapport
}

ESSAY

\section{LEIV M. HOVE}

E-post: leiv.hove@outlook.com

Leiv M. Hove er professor dr.med., seksjonsoverlege ortopedisk kirurgi, Ortopedisk avdeling, Haukeland universitetssykehus og Klinisk institutt 1, Universitetet i Bergen. Forfatter har fylt ut ICMJE-skjemaet og oppgir ingen interessekonflikter.

\section{INGE GLAMBEK}

Inge Glambek er seksjonsoverlege generell kirurgi, universitetslektor, spesialist i generell kirurgi, karkirurgi og thoraxkirurgi, Kirurgisk avdeling, Haraldsplass Diakonale Sykehus og Klinisk institutt 1, Universitetet i Bergen.

Forfatter har fylt ut ICMJE-skjemaet og oppgir ingen interessekonflikter.

\section{INGE MORILD}

Inge Morild er professor i rettsmedisin og overlege i patologi, Gades laboratorium for patologi, Klinisk institutt 1, Universitetet i Bergen og Avdeling for patologi, Haukeland universitetssykehus. Forfatter har fylt ut ICMJE-skjemaet og oppgir ingen interessekonflikter.

Hva døde Tordenskiold av? Vi presenterer her en skadekirurgisk og rettsmedisinsk vurdering av obduksjonsrapporten. 


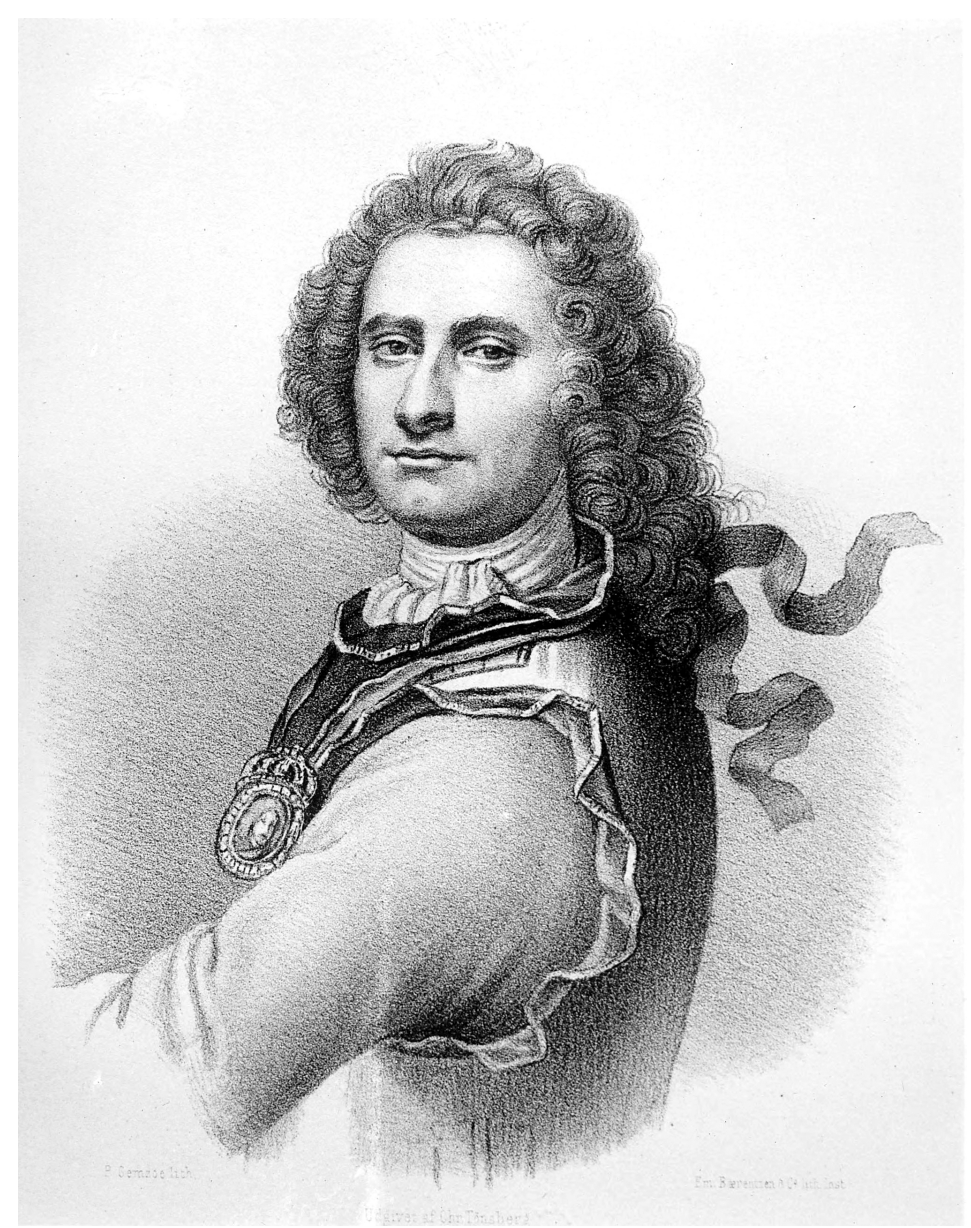

Foto: Nasjonalbiblioteket/Anders Beer Wilse.

Peter Wessel Tordenskiold døde bare 30 år gammel (1690-1720). I løpet av sitt korte liv opplevde han en usedvanlig karriere. Han ble adlet som 27-åring og to år senere forfremmet til viseadmiral. Da Den store nordiske krig (170o-1721) var over (1), ble den dansk-norske flåten lagt i opplag, og Tordenskiold gikk i land. Men freden gjorde ham rastløs, og han bega seg ut på en lang reise rundt i Europa. Under et selskap i fyrstedømmet Hannover kom han opp i en krangel som ledet til en duell som førte til hans $d ø d(2-4)$.

Overlege Kathrin Pulverer har for første gang oversatt obduksjonsrapporten til norsk. Vi har foretatt en kirurgisk og rettsmedisinsk vurdering av de påførte skadene slik de fremkommer i obduksjonsrapporten.

\section{Selskapet 9. november - opptakten til Tordenskiolds død}

Europareisens mål er ukjent, og Tordenskiold reiste med hest og vogn sammen med kaptein Ployart, sin kammertjener Christian Nielsen Kold (1693-1762), en kusk og en løpedreng.

Første delmål på reisen var fyrstedømmet Hannover der den engelske kong George 1. var kurfyrste, og der Tordenskiold og hans følge innlosjerte seg på to værelser hos stabskirurg Wrede i Markstrasse. Opptakten til duellen skjedde under et selskap den 9. november hos kammerpresident Gørtz i hans bolig i Fürstenhof, der kong Georg også var til stede. Da middagen var omme, ankom en adelsmann fra tidligere svensk Livland, Jacob Axel Stäel von Holstein (1680-1730), som hadde gjort tjeneste som oberst i den svenske armeen. I løpet av kvelden kom Tordenskiold og Stäel i krangel - Tordenskiold kalte Stäel for falskspiller, og Stäel kalte Tordenskiold for matros. Det ble håndgemeng, og Tordenskiold ga Stäel en blåveis og flere andre slag. Da flere fra selskapet fikk skilt de to, utfordret den forslåtte Stäel Tordenskiold til duell, for å «gjenopprette sin ære» (2-4).

Det er vanskelig å redegjøre eksakt for historien rundt dueller, ettersom tradisjonene har skiftet, og det var geografiske forskjeller. På Kontinentet var blanke våpen vanligst. Sverdet (sabel, kårde) var symbolet på mandighet og ære. Duellen ble oftest utkjempet i penere 
hverdagstøy, og man stoppet ved første treff. Denne tradisjonen med et riss på kinnet eller et lite kutt $i$ armen holdt seg i bl.a. tyske militærforlegninger og studentforeninger helt frem til første verdenskrig. Bl.a. finnes det en beretning om at Martin Luther under et av sine første år på universitet holdt på å omkomme under en duell med en studievenn, da han fikk et stikk i leggen og holdt på å forblø (5).

En kårde var ikke som dagens konkurransekårder, uten knivsegg. De militære kårdene var på 170o-tallet en rett sabel med egg på begge sider av klingen (6). En av Tordenskiolds mange kårder (sabler) oppbevares i dag på Marinemuseet i Horten (se figur). Den har flere kryss i treskjeftet som indikerer hvor mange ganger Tordenskiold hadde brukt den i duell. Vi har også en skriftlig beretning om en duell mellom Tordenskiold og en navngitt medstudent under tiden på sjøkrigsskolen i København (4).

Det er derfor høyst tvilsomt om duellen som tok livet av Tordenskiold, skulle være en «duell på liv og død». Sannsynligvis var det planlagt, i tråd med datidens tradisjon, å stanse ved første treff. Slik omtales den også av den historiske forfatter Casper Peter Rothe (1724-1784) i den første biografien om Tordenskiold: «det skal være en lille proforma fægtning, for at give oberst Stäel nogen Revange» (7).

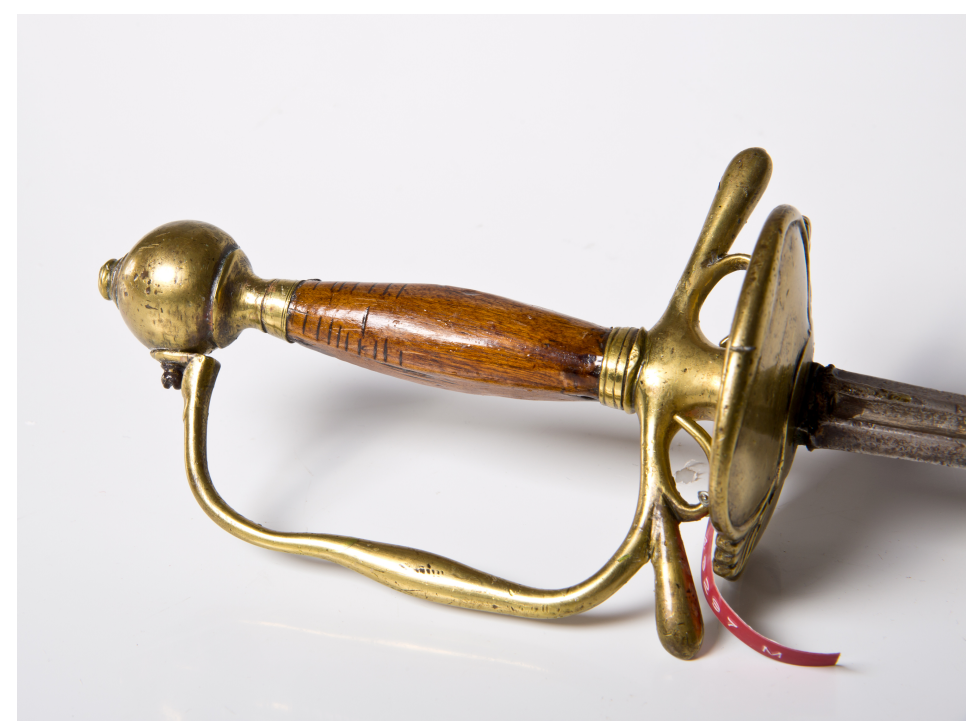

Tordenskiolds kårde som oppbevares på Marinemuseet $i$ Horten. Der kan den sees i deres faste utstilling med flere av hans andre våpen. Foto: Marinemuseet $i$ Horten.

Beretningene om at Tordenskiold utkjempet duellen med en liten paradekårde, mens Stäel brukte kavaleriets lange sabel, er bare en myte. Kun kammertjener Kold skriver dette i sin beretning mer enn 20 år senere. Alle andre beretninger omtaler like våpen. Det var dessuten henimot 20 offiserer fra Hannover til stede som tilskuere. De ville selvsagt ikke akseptert at det var ulike våpen. Den sabelen Tordenskiold angivelig brukte i duellen, ble for øvrig funnet i Tyskland i 1990-årene. Klingen målte 87,6 cm (4).

\section{Duellen}

Tordenskiold ble oppsøkt i sin midlertidige residens dagen etter det famøse selskapet.

Duellen ble avtalt til om morgenen den 12. november. Kvelden før var Tordenskiold i selskap hos baron Bülow, der han spiste, drakk og moret seg, Han virket angivelig helt uberørt av at han skulle utkjempe en duell neste morgen $(3,4)$.

Kl. o5 om morgenen ble han hentet av den utpekte sekundanten, oberst von Münchhausen (far til lystløgner-baronen). De dro til landsbyen Gleidingen ca. $15 \mathrm{~km}$ sør for Hannover. Duellen ble utkjempet i en gress-skråning ved en myr. Der ventet oberst Stäel og hans sekundant, den svensk-franske offiseren André Sicre. I tillegg til de om lag 20 offiserene fra Hannover var de to sekundantene og kammertjener Kold tilskuere. Det var også en kirurg til stede, sannsynligvis stabskirurg Wrede, der Tordenskiold og hans følge var innkvartert.

Det foreligger flere øyevitneskildringer som alle er ganske like når det gjelder selve 
hendelsesforløpet: Duellen varte bare ca. ett minutt. Stäel angrep, og Tordenskiold retirerte (trakk seg bakover) 3-4 skritt. Tordenskiold angrep så hastig (styrtet frem) med kården hevet i høyre hånd for et støt mot Stäel. Denne nådde å få opp sin kårde til et motstøt med nærmest strak arm og traff den angripende Tordenskiold i hans høyre side like over brystvorten. Støtet var kraftig. Kården gikk langt inn i brystkassen. Tordenskiold falt. Han utbrøt «Ich habe genug. Mein Arm ist ab.» (Jeg har fått nok. Min arm er av.) Kirurgen stormet til og prøvde å stoppe den kraftige blødningen fra stikkåpningen i brystkassen. Tordenskiold døde i løpet av 3-4 minutter (4).

Oberst Stäel von Holstein var 10 år eldre enn Tordenskiold. Han var overvektig, nærsynt og dårlig trent. Da Tordenskiold (i bakrus?) gjorde sitt hastige fremstøt, fikk obersten løftet sabelen. Mange mener at han bevisst siktet mot Tordenskiolds overarm for å forårsake en sårskade der, slik at duellen kunne avsluttes med ham som seierherre, i tråd med tradisjonen om duell til første blødning. Dette passer også med Tordenskiolds rop umiddelbart etter støtet: "Jeg har fått nok. Min arm er av.»

Eller som Stäel skrev tre dager senere i sin rapport: «Jeg var så uheldig å gi ham et støt nær høyre brystvorte. Han ropte Halt! Jeg stanset øyeblikkelig, han ble undersøkt, og det viste seg at den store pulsåre var overskåret, hvorpå han øyeblikkelig utåndet» (4, 8).

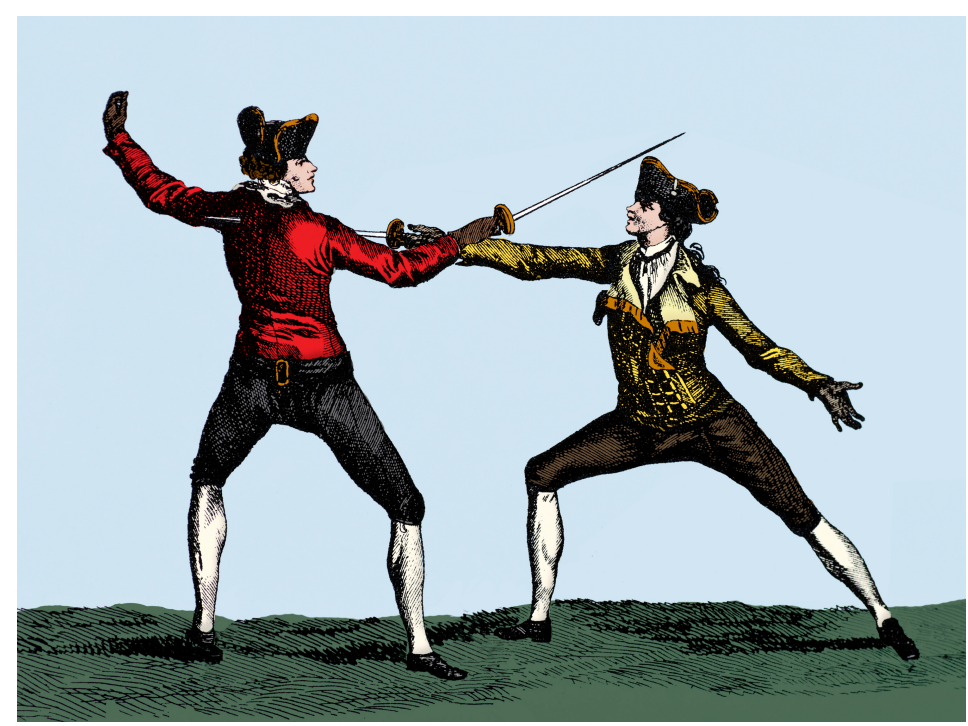

Stikket gikk inn i brystkassen, ovenfor høyre brystvorte, og gjennom høyre lunge. Illustrasjonsfoto: Flory/iStock, endret og fargelagt hos Tidsskriftet.

Før den lange hjemtransporten til København måtte liket balsameres. Dette ble organisert av den danske legasjonssekretæren von Jessen som kom fra Hannover to dager senere. Før balsameringen ble det fortatt rettsmedisinsk obduksjon av tre tyske leger (8).

\section{Obduksjonsrapporten}

Lenge trodde man at obduksjonsrapporten ikke eksisterte. Den ble imidlertid gjenoppdaget for noen tiår siden som et håndskrevet dokument i Tordenskiolds egen notisbok. Teksten var skrevet med en slags blyant (sølvstift), dels med gotiske bokstaver på (gammel) tysk, de medisinske ord med latinske bokstaver, og var i tidens løp blitt nokså uleselig. I 1950-årene lyktes det to danske leger, ved hjelp av en spesiell fototeknisk metode, å få kopiert teksten til tydeligere skrift (9). Med spesiallupe lyktes det da å tyde teksten relativt bra (10). Flere historikere har siden kommet med alternative tydningsforslag (11), men den opprinnelige ser ut til å ha blitt stående (8).

\section{Ramme 1}

Notisbokens side 4-6, obduksjonsrapporten, oversatt til norsk av overlege Kathrin Pulverer, Ortopedisk avdeling, Haukeland universitetssykehus. (Oversettelsen er basert på 
referansene 8,10 og 11.$)$

(Et kutt) på innsiden av høyre arm som måler cirka 3 fingerbredder $\times 4$ fingerbredder $\mathrm{i}$ lengden i Intugmenta universalia (= huden).

Videre (ses) en nokså betydelig lesjon av musculus deltoideus som er lokalisert her og kuttet ca. 3 fingre bredt.

(Kuttet/stikket) stopper ved venstre skulder ca. 1 zoll $(=2,54 \mathrm{~cm})$ bak venstre clavicula.

(Kuttet forløper) fra bak (siden) på motsatt (= venstre) side gjennom pleura på samme side (= høyre) gjennom lungelobum cirka 2 zoll $(=5,08 \mathrm{~cm})$ kuttet inn i aorta.

Gjennom lobum, omtrent 4 zoll lang $(=10,16 \mathrm{~cm})$ helt gjennom pericardium på samme side (tre underskrifter)

Den håndskrevne rapporten er signert av tre leger, den ene kan se ut som het Meyer. Obduksjonsrapporten ser ut til å være skrevet etter diktat, sannsynligvis av en ikke medisinsk kyndig person (8). Det synes også som dikteringen har gått litt fort for skriveren. Flere ord er ikke fullført, og mange synes utelatt. Man antar at skriveren er den danske legasjonssekretæren von Jessen, som skulle organisere balsameringen og hjemsendelsen (8).

\section{Kirurgisk beskrivelse av skadene}

Kården (sabelen) gikk altså inn i høyre side av thorax. På veien inn skadet den overarmen der den laget en lesjon ( 3 fingerbredder $\times 4$ fingerbredder) i musculus deltoideus, der denne går ned på overarmen.

Stikk-kanalen gikk gjennom brystveggen, den perforerte høyre lunge og perikard og laget en 2 tommer lang lesjon i aorta. Stikk-kanalen gikk videre gjennom venstre del av brystkassen og kom ut bak venstre clavicula og endte en tomme bak denne - altså en retning nedenfra og litt oppover i kroppen, tvers gjennom hele brystkassen. Denne beskrivelsen kan passe med enkelte øyevitneskildringer som beskrev at nesten hele kårdens klinge var inne i kroppen (4).

Det er imidlertid også uoverensstemmelser mellom kildene. I von Jessens rapport, datert den 15. november, altså tre dager senere, skriver han at «han den foregående dag hadde vært til stede ved likets balsamering. Stäels klinge hadde gått inn mellom første og annet ribben, var trengt gjennom lungen inntil ryggraden og hadde overskåret begge arterier» (8).

Innstikk mellom 1. og 2. ribben er ikke angitt av obdusentene, heller ikke at stikk-kanalen stoppet ved ryggraden. Tvert imot beskriver obduksjonsrapporten at stikk-kanalen fortsatte gjennom venstre thorax-halvdel bak clavicula og stoppet nær venstre skulder. Von Jessen angir også at begge arterier var overskåret, mens obduksjonsrapporten bare skriver aorta.

\section{Rettsmedisinsk vurdering}

Siden det også var en nokså stor skade på armen, kan det passe med at armen har vært strukket frem, og at det har oppstått et skarpkantet sår, kanskje en blanding av et skjære- og stikksår, i muskulaturen øverst mot skulderen. En kårde, med rund form, ville gitt et rundt sår, mens en tveegget kårde er bedre forenlig med et skjæresår i armen, som beskrives som 3-4 fingerbredder stort, og som er en nokså betydelig lesjon av musculus deltoideus. Kanalen går også fra side til side av thorax, forenlig med at Tordenskiold har hatt høyre del av sin brystkasse vendt mot motstanderen, slik man gjerne har i fektesituasjoner.

Å fastslå duellantenes eksakte posisjoner er ikke mulig, men en stikk-kanal litt oppover i Tordenskiolds kropp kan vel være forenlig med et stikk fra en håndholdt kårde/sabel. Stikket som har gått inn i brystkassen, ovenfor høyre brystvorte, har gått gjennom høyre lunge. En slik skade er i seg selv ofte livstruende, gjerne med pneumothorax, men er ikke umiddelbart dødelig. Stikket har videre gått inn i perikard og deretter skadet aorta (eller kanskje som legasjonssekretæren skriver: «begge arterier», = aorta og arteria pulmonalis?, som begge ligger inne i perikard). Siden det ikke er omtalt noen skade på venstre lunge, 
taler det for at stikk-kanalen har hatt retning litt oppover, og kanskje passert like ovenfor lungetoppen. Spørsmålet er om det også har foreligget hjertetamponade. Skaden i aorta skal ha vært ca. $5 \mathrm{~cm}$, noe som kan bety en ganske stor rift i hjerteposen. Dette minsker sjansen for hjertetamponade fordi blodet renner ut i pleurahulen, slik at hjertet fortsatt kan utføre sin pumpefunksjon. Litt blod vil som regel finnes i perikard, men ofte ikke nok til å være av funksjonell betydning.

Det er vanskelig å anslå sikkert hvor lenge man kan overleve med en slik skade, men skaden vil medføre blodtrykksfall, med nedsatt cerebral sirkulasjon, og bevissthetstap i løpet av meget kort tid. Både ved hjertetamponade og ved rent blodtap fra aorta vil døden kunne inntre i løpet av få minutter, noe som er forenlig med opplysningene fra tilskuerne.

\section{En hurtig blødningsdød}

Til tross for at obduksjonsrapporten har vært tilgjengelig i mer enn femti år, har den tilsynelatende ikke vært gjenstand for omfattende medisinske vurderinger. Vi har kun funnet én publikasjon - publisert i Tidsskriftet - som på medisinsk grunnlag prøver å vurdere rapporten (8).

Hagelsten legger til grunn at drapsvåpenet, en kårde, kun var et stikkvåpen. Uten å analysere beskrivelsen i obduksjonsrapporten nærmere mener han at «den må være forkert», og at det er påfallende at et stikkvåpen kan forårsake «en 3 finger bred lesjon i deltoideus». Han mener at døden, forårsaket av et stikkvåpen, basert på øyevitneskildringen, måtte skyldes trykkpneumothorax. Han vektlegger særlig kammertjener Kolds beretning, skrevet mer enn 20 år etter hendelsen: «Stahl lot hannem en stif Arm, gjorde og tillige et Udfald i det samme mod Tordenskiold, som således var kommet hans Klinge for nær, at han stødte Tordenskiold ind under hans høyre Arm i en Qvart, saa Klingen igjen gik bag ud af Skulderen, og trekkede den derpaa igien tilbage i en Ters» $(7,8)$.

Basert på denne beskrivelsen har andre ment at siden kården gikk inn på høyre side av brystkassen og ut bak høyreskulder, måtte døden være forårsaket av blodtap på grunn av lesjon i høyre arteria subclavia.

Etter å ha analysert obduksjonsrapporten vil vi konkludere annerledes. Skadene forårsaket av en tveegget sabel, stukket tvers igjennom brystkassen med omfattende skader av lunge, perikard og aorta, var selvsagt dødelige og forårsaket en hurtig blødningsdød. Øyevitneskildringene beskrev en svær blødning som kirurgen ikke klarte å stoppe. Åstedsgranskingen noen dager senere av de lokale myndighetene viste også store mengder blod på bakken $(4,8)$.

De fleste moderne danske historikere mener i dag at Tordenskiolds død minner mest av alt om et uhell under en duell der de to duellantene bare ville "pirke i hverandre», altså en æresduell uten hensikt å drepe, bare gjenopprette æren $(3,4,12)$ : Kanskje «trådte Tordenskiold simpelthen forkert der han styrtede frem i det dugvåde græs denne tidlige høstmorgen, og kom for hurtig på den fiendtlige kårde». Sagt på en annen måte: Tordenskiold snublet inn i døden.

LITTERATUR:

1. Lindgjerdet F. Norge og Den store nordiske krigen 1700-1721. Skallestad: Ares Forlag, 2016.

2. Eilstrup P. Tordenskiold. Peter Wessel og hans tid. København/Oslo: Forlaget Union/Det nye forlaget, 1967 .

3. Andersen DH. Mannsmod og kongegunst. En biografi om Peter Wessel Tordenskiold. København: Aschehoug Dansk Forlag, 2004.

4. Andersen DH. Peter Wessel Tordenskiold. København: Lindhardt og Ringhof, 2015.

5. Neumann HJ. Luthers Leiden. Die Krankeheitgeschichte des Reformators. Berlin: Wichern-Verlag, 
2016.

6. Norheim PT. Våpen i Norge. Fra spyd og luntelåsmuskett til Krag Jørgensen og bajonetter. Oslo: Cappelen Damm Faktum, 2011: 53-91.

7. Rothe CP. Forsøg til navnkunnige danske mænds livs- og levnedsbeskrivelse. II stykke: Den danske søe-heldt og vice-admiral Peter Tordenskiold. Trykt i Kiøbenhavn på Authoris Bekostning 1747-50. (Sitert i Andersen DH. Peter Wessel Tordenskiold. København: Lindhardt og Ringhof, 2015).

8. Hagelsten JO. Tordenskiolds død-medicinsk set. Tidsskr Nor Lægeforen 1991; 111: 962 - 5. [PubMed] 9. Jensen VR. Tordenskiolds død. Med Forum 1952; 5:340 - 8.

10. Petersen H. Tydningen av Tordenskiolds sektionsbeskrivelse. Med Forum 1953; 6: 225 - 6.

11. Schmidt JB. Tordenskjolds død. Dansk Historisk Tidsskrift 1956; Bind 11: Rekke 4 (1953-1956).

12. Bjerg HC. Peter Tordenskiold. Dansk marinehistorisk bibliografi. Marinehistorisk selskabs skrifter 1975; XII: 117-37. Gjengitt i Dansk Biografisk Leksikon, København 1979: 84.

Publisert: 27. september 2018. Tidsskr Nor Legeforen. DOI: 10.4045/tidsskr.18.0211

(C) Tidsskrift for Den norske legeforening 2020. Lastet ned fra tidsskriftet.no 